\title{
Effects of arousal and credibility on learning and persuasion
}

\author{
CLYDE HENDRICK and DAVID R. SHAFFER \\ Kent State University, Kent, Ohio 44240
}

This study explored the joint effects of extraneous arousal and communicator credibility on acceptance and learning of a persuasive communication. Ss listened to a taped speech under either average volume (low arousal) or very high volume (high arousal). The speaker was either high or low in credibility. Males and females reacted very differently to the situation. Females were more persuaded under low arousal than under high arousal, but there were no differences for males. Credibility had no effect. An unusual learning effect emerged. There was a Credibility by Arousal interaction that had the same form for both sexes. The attitude results were given a dissonance interpretation.

Recently Hendrick \& Borden (1970) found that fear arousal extraneous to the content of a communication affected acceptance of the communication. The results for males confirmed previous findings by Helmreich, Kuiken, \& Collins (1968) that birth order interacted with level of fear arousal in determining attitude change. However, an attempt to manipulate communicator credibility had no effect on persuasion, contrasting with results reported by Sigall \& Helmreich (1969).

In the present study, extraneous arousal and communicator credibility were varied orthogonally, and their effects on learning and persuasion were assessed. The study of fear-arousing communications is an important area of attitudinal research (McGuire, 1966). The major problem has been that fear arousal has always been confounded with changes in the content of persuasive messages. Therefore, it is unclear whether differences in persuasion were due to different levels of fear or to differences in informational content of different messages. There are now several studies showing that a source of fear extraneous to the comriunication content does have an effect on persuasion. However, the effects are unstable across the several experiments, and it is unclear how fear emotion per se mediates persuasion.

Hendrick ${ }^{1}$ proposed a general hypothesis, that increases in any kind of arousal should, under certain conditions, lead to increased persuasion. Arousal should have effects on the processing of incoming information. Ss in a highly aroused state, relative to nonaroused $\mathrm{Ss}$, might overlook flaws in the message, fail to produce counterarguments against the message, and overlook the significance of the communicator's credibility. Therefore, greater persuasion should be generally obtained with increased arousal. Further, such persuasion should not be restricted to fear arousal, but should be obtained with many types of strong arousal. If Ss do overlook relevant cues when highly aroused, then variation in communicator credibility should have less effect under high arousal than under low arousal. This interaction prediction was tested in the present experiment.

An attempt was made to generate an arousal state more general than fear arousal (Hendrick \& Borden, 1970). Such arousal was manipulated by having Ss listen to a persuasive speech under different conditions of loudness. Ss listened to the speech under either normal volume or very intense volume. Intense volume should have created a relatively unpleasant arousal state that could not be specifically labeled fear, anger, etc. Arousal generated in this manner was independent of the specific content of the speech, but was contiguous in time with the content.

Credibility of the speaker was varied by the way the speaker was introduced. In addition to acceptance of the speech, learning of the communication was a dependent variable of equal interest. It was possible that listening under intense volume might set up defensive avoidance tendencies that would result in reduced learning relative to low-volume conditions. METHOD

College students listened to a taped speech under the guise of participating in an experiment concerned with discovering the factors that increase a student's efficiency in learning. The speaker was introduced in such a way as to make him either high or low in credibility. After the introduction, Ss listened to a speech that was either very loud or moderate in volume. When the speech was finished, Ss completed several questionnaires designed to measure recall, attitude toward the issue, evaluation of the issue, and subjective mood during the speech.

Subjects and Design

Eighty students from a section of introductory psychology participated as Ss.
There were 40 males and 40 females. Ss participated in same-sex pairs.

The design of the experiment was a 2 by 2 by 2 factorial with sex as a $S$ variable and speech loudness and communicator credibility as manipulated variables. Ss were randomly assigned to experimental conditions within the limitation of an equal number per condition.

\section{Stimulus Tapes}

Taped recordings were made which contained a statement of the purpose of the experiment, instructions to the Ss, an introduction of the speaker, and a 5-min speech, in that order. Two tapes were prepared which were identical except for the introduction of the speaker.

The purpose was described as an attempt to discover the optimal conditions for learning material presented in lectures. Ss were told that they would listen to a 5 -min lecture over headphones and then complete several questionnaires that measured the effectiveness of their listening.

The introduction of the speaker served as the manipulation of credibility. In the high-credible version, the speech was attributed to Dr. Paul Striker, a distinguished professor of radiology. In the low-credible version, the speech was attributed to a high school student who had prepared the speech for a debate class. The introduction contained 112 words for the high-credible source and 58 words for the low-credible source.

The speech, based on one of McGuire's (1964) communications on health practices, was an attack on the use of annual chest $\mathrm{X}$-rays to detect tuberculosis. The speech contained three basic arguments against $X$-rays, and each argument was supported by an impressive array of evidence. The speech was recorded by a person other than the $E$, who recorded the instructions and introduction of the speaker.

\section{Questionnaires}

The questionnaires included a 10-item multiple-choice quiz to assess recall, a 7-item speech evaluation form, a mood rating scale, and an attitude scale. The evaluation form contained ratings of the interest, difficulty, bias, scientific quality, truthfulness, articulation, and reasonableness of the speech. The mood scale contained 16 adjectives (e.g., angry, carefree, afraid, etc.), on which Ss rated their moods during the speech. The ratings for the latter two questionnaires were made on 9-point scales. The attitude scale contained 12 items, 4 of which were relevant to the issue of $\mathrm{X}$-rays. Each item was rated on a 15-point scale, and the sum of the 4 X-ray items was the measure of attitude on the issue. 
Procedure

When Ss arrived for the experiment, they were seated at a table containing a tape recorder and two sets of headphones. The $\mathrm{E}$ explained that the instructions were recorded in order to ensure uniformity across Ss. The taped purpose, initial instructions, and the speaker's introduction were then played for the Ss. At the conclusion of this section of the tape, the $E$ turned off the recorder and asked if there were any questions. Then, Ss were asked to put on the headphones. At this point, the $E$ adjusted the volume level for the speech, depending on the sound conditions to which a particular pair of Ss had been assigned. The volume level was turned up to maximum for $S s$ in the high-volume condition. Sound intensity was measured directly from the output of the headphones with a General Radio sound-level meter. The sound level ranged from 98 to $114 \mathrm{~dB}$. Pretesting indicated that this level was unpleasant but not painful. For $\mathrm{Ss}$ in the moderate-volume condition, the sound level ranged from 70 to $82 \mathrm{~dB}$. This setting seemed to give comfortable reception of the.speech. The ambient noise level was recorded as $60 \mathrm{~dB}$.

After listening to the speech, Ss completed the four questionnaires, and were then debriefed and asked not to discuss the experiment with anyone.

\section{RESULTS}

The results of the experiment are presented under four headings: mood ratings, communication evaluation, recall, and attitude. The results will usually be presented separately for each sex because the two sexes reacted very differently to the situation on many of the measures. Unless otherwise indicated, significance tests were made by analysis of variance.

\section{Mood Ratings}

There were 16 different mood words altogether. There were no differences for 4 of these words (jittery, cheerful, afraid, and grouchy) between any of the experimental conditions. There were four other mood words relevant to negative emotional arousal. Males listening to the very loud speech rated themselves as more irritated $(\mathrm{p}<.004)$, annoyed $(\mathrm{p}<.03)$, tense $(\mathrm{p}<.005)$, and angry $(\mathrm{p}<.08)$ than males listening to the speech under moderate volume. Females did not show a similar expression of hostility since there were no differences between volume conditions for females on any of these four moods. Females did indicate that they were significantly more dazed $(\mathrm{p}<.03)$ under high volume than under low volume.

The manipulation of credibility affected a few of the mood ratings. Ss listening to the high-credible speaker rated themselves as more helpless $(\mathrm{p}<.008)$ and restless
Table 1

\begin{tabular}{llccc}
\multicolumn{5}{c}{ Mean Recall Scores } \\
$\begin{array}{llcc}\text { Credi- } \\
\text { bility }\end{array}$ & Volume & M & F & Total \\
\hline High & High & 9.1 & 8.8 & 8.95 \\
High & Noderate & 8.2 & 7.4 & 7.80 \\
Low & High & 8.0 & 8.1 & 8.05 \\
Low & Moderate & 8.9 & 8.4 & 8.65 \\
\hline
\end{tabular}

Note $-N=10$ per cell

$(p<.008)$ than Ss listening to the low-credible speaker.

There was a significant Volume by Credibility interaction for alamed and overwhelmed. Males were more alarmed $(p<.05)$ and overwhelmed $(p<.05)$ when listening to the high-credible speaker under high volume than under moderate volume, but the direction of the difference was reversed when listening to the low-credible speaker. The interaction for females was not significant on either measure.

\section{Communication Evaluation}

Females perceived the high-credible speaker as giving more reasonable arguments than the low-credible speaker $(p<.01)$. The trend for males was in the same direction $(p<.21)$. The main effect of credibility for both sexes combined approached significance $(\mathrm{p}<.07)$. For both sexes combined, the low-credible speaker was rated as more difficult to understand than the high-credible speaker $(\mathrm{p}<.05)$. For the males, there was a Volume by Credibility interaction on ratings of interest $(p<.04)$. Males listening to the high-credible speaker were more interested under high than under moderate volume, but this difference was reversed when listening to the low-credible speaker. Finally, females rated the speeches as more interesting $(p<.02)$ and more well-spoken $(\mathrm{p}<.05)$ than did the males. Recall

The recall scores could vary between 0 and 10. The mean recall scores for the experimental conditions are shown separately for each sex in Table 1. Inspection of the means indicates an interaction between credibility and volume that had the same form for both sexes. Under high-volume conditions, recall was relatively better when listening to a high-credible speaker than when listening to a low-credible speaker. Just the opposite

Table 2

Mean Attitude Scores

\begin{tabular}{llccc}
\hline & & \multicolumn{2}{c}{ Sex } & \\
\cline { 3 - 4 } $\begin{array}{l}\text { Credi- } \\
\text { bility }\end{array}$ & Volume & M & F & Total \\
\hline High & High & 20.5 & 29.6 & 25.05 \\
High & Moderate & 20.1 & 17.1 & 18.60 \\
Low & High & 19.9 & 29.2 & 24.55 \\
Low & Hoderate & 21.0 & 22.5 & 21.75 \\
\hline
\end{tabular}

Note-N=10 per cell. The lower the score. the greater the persuasion. was true, however, for the moderate-volume conditions. For each sex considered separately, the ineraction was significant for males $(p<.03)$ and for females $(p<.02)$. For both sexes combined, the interaction was significant at the .001 level. This combined interaction is reflected in the average means recorded in the last column of Table 1. Individual comparisons were made between these total means by the Newman-Keuls test. The mean of 8.95 for the high-credible, high-volume condition was significantly larger $(p<.01)$ than the mean of 7.80 for the high-credible, moderate-volume condition. Also, the high-credible, high-volume mean was significantly larger $(\mathrm{p}<.05)$ than the mean of 8.05 for the low-credible. high-volume condition. In the moderate-volume conditions, the mean of 8.65 for low credibility was significantly larger $(p<.05)$ than the mean of 7.80 for high credibility. When the source was low in credibility, the difference in recall between the high-volume and the moderate-volume conditions was not significant.

\section{Attitude}

The mean attitude score on the X-ray issue for each experimental condition is shown separately for each sex in Table 2. The scores could range between 4 and 60 , and the lower the score the greater the acceptance of the recommendations. The mean scores varied from a low of 17.1 to a high of 29.6. The average score on the other health issues (penicillin and tooth-brushing) was 45.41. Assuming initial comparability of belief level, the speech, overall, was quite persuasive.

The main question concerned differences between experimental conditions. Analysis of variance revealed that for the males there were no significant differences among the experimental conditions. For the females, however, there was a significant main effect of volume. Females were more persuaded under moderate volume than under high volume $(p<.05)$. Neither the main effect of credibility nor the interaction were significant.

An analysis of covariance was performed on the attitude data with recall scores as the covariate. This analysis did not make any difference in the results. The difference between high and moderate volume for females was somewhat greater, but otherwise there were no differences.

\section{DISCUSSION}

The data from the mood ratings incicated that the variation in volume did have arousal consequences. Males. particularly, indicated more negative 
arousal when exposed to the very loud speech. The females gave only slight indications of increased negative arousal with increased speech loudness. Whether this represents a genuine effect or simply a tendency for females to give more socially desirable responses cannot be determined from the available data.

The mood and evaluation ratings also provided evidence that credibility of the speaker was successfully varied. Ss rated themselves as more helpless when listening to the high-credible speaker. This effect might be interpreted to mean that they felt more vulnerable to his arguments. Also, Ss felt more restless when listening to the high-credible speaker. Further evidence was provided by the trend toward perceiving the high-credible source as giving more reasonable arguments and as easier to understand.

Since arousal and credibility both appeared to have been successfully manipulated, it was surprising that credibility had no effect on persuasion. A similar failure of the credibility manipulation was obtained by Hendrick \& Borden (1970) using a similar issue. Such a failure is puzzling since the effect of credibility is one of the best established results in attitude research. The failure may be due to the factual issue that was used. Insko (1967) noted that a few studies have not found attitude change as a function of variation in credibility. Insko suggested that the influence of source credibility may be inversely proportional to the logical soundness of the communication. If a communication is very logical and well supported by evidence, variation in credibility may not make much difference. This interesting possibility remains to be tested.

The attitude results for females were consistent with the results for females obtained by Hendrick \& Borden (1970). In both experiments, females were less persuaded under high arousal than under low arousal. The nature of these sex differences is unclear, but they do not support the hypothesis of a positive relation between arousal and persuasion. In fact, the results for females provide strong support for Janis \& Feshbach's (1953) finding of an inverse relation between fear and persuasion. Most recent research has strongly questioned Janis and Feshbach's results (McGuire, 1966).

The pattern of results for the mood ratings and the attitude data considered jointly suggests an interesting interpretation of the attitude data. Inspection of the eight means in Table 2 reveals that six of the means are quite similar. Males in all four conditions and females in the two moderate-volume conditions were all persuaded to about the same extent. Females in the two high-volume conditions sho:ved a relative resistance to persuasion since their means were higher. Listening to the speech under intense sound may have created a state of cognitive dissonance (Festinger, 1957) in the Ss. The males resolved their dissonance by becoming hostile. With dissonance thus reduced, they were just as vulnerable to persuasion as males in the moderate-volume conditions. However, females apparently did not reduce much of their dissonance by hostility. Instead, females in the intense-sound conditions reduced dissonance by resisting the communication, thereby being persuaded less than females in the moderate-sound conditions.

The most unusual result of the experiment was the outcome for recall. The interaction between credibility and volume was not expected and is not easily explained. The results are unusual because no previous experiments have found credibility of the source to affect learning of the communication. McCroskey (1968) noted this lack of a relation between source credibility and learning, but still felt intuitively that a high credibility source should command greater comprehension. The pattern of the recall means shown in Table 1 reveals a more complicated story, however. Under high sound intensity, listening to the high-credible source did indeed result in better learning than listening to the low-credible source.
However, under moderate sound intensity (most comparable to everyday listening conditions), listening to the low-credible source resulted in better learning than listening to the high-credible source. An explanation for these learning effects must await future research.

\section{REFERENCES}

FESTINGER, L. $A$ theory of cognitive dissonance. Evanston, ill: Row, Peterson, 1957.

HELMREICH, R., KUIKEN, D., \& COLLINS, B. Effects of stress and birth order on attitude change. Journal of Personality, 1968, 36, 466-473.

HENDRICK, C., \& BORDEN, R. Effects of extraneous fear arousal and birth order on attitude change. Psychonomic Science, 1970, 18, 225-226.

INSKO, C. A. Theories of attitude change. New York: Appleton-Century-Crofts, 1967.

JANIS, I. \& FESHBACH, S. Effects of fear-arousing communications. Journal of Abnormal \& Social Psychology, 1953, 48, 78-92.

McCROSKEY, J. C. An introduction to rhetorical communication. Englewood Cliffs, N.J: Prentice-Hall, 1968.

MCGUIRE, W. J. Inducing resistance to persuasion. In L. Berkowitz (Ed.), Advances in experimental social psychology. Vol. 1. New York: Academic Press, 1964. Pp. 191-229.

McGUIRE, W. J. Attitudes and opinions. Annual Review of Psychology, 1966, 17, 475-514.

SIGALL, H., \& HELMREICH, R. Opinion change as a function of stress and communicator credibility. Journal of Experimental Social Psychology, 1969, 5, 70-78.

\section{NOTE}

1. Hendrick, C. Fear arousal and attitude change: A general hypothesis. Unpublished manuscript, Kent State University, 1968.

\title{
Variable length consonant stimuli in a "Peterson \& Peterson" short-term memory paradigm
}

\author{
B. JAMES STARR, ${ }^{*}$ Howard University, Washington, D.C. 20001 \\ GILBERT J. HARRIS, New York State Institute for Research in \\ Mental Retardation, Staten Island, N.Y. 10314 \\ and
}

ROBERT ARONOFF, State Unjversity of New York at Buffalo, Buffalo, N.Y. 14226

The effects of stimulus length, interpolated task interval, and rehearsal upon recall in a "Peterson \& Peterson" short-term memory paradigm were tested. All three main effects, but none of the interactions attained significance. The superiority of self-initiated as opposed to E-paced rehearsal was suggested as was the increased necessity for any type of rehearsal as stimulus length increased.

The rapid forgetting that characterizes

*Thanks are due to Dr. Roy Lachman and Dr. Hayne Reese for helpful suggestions regarding the design of the present study. short-term memory may be strikingly demonstrated utilizing an experimental paradigm developed by Peterson \& Peterson (1959). S was presented with a 